\title{
The Impact of eHRM Practice on Organizational Performance: Investigating the Effect of Job Satisfaction of HRM Professionals
}

\author{
${ }^{1}$ Abdul Kadar Muhammad Masum, ${ }^{2}$ Abdullah Mohammad Ahsanul Mamun, \\ ${ }^{3}$ Mohammad Shariful Islam and ${ }^{4}$ Loo-See Beh \\ ${ }^{1}$ Department of Computer Science and Engineering, International Islamic University Chittagong, Chittagong, Bangladesh \\ ${ }^{2}$ Department of Business Administration, International Islamic University Chittagong, Chittagong, Bangladesh \\ ${ }^{3}$ Department of Business Administration, Bangladesh Army International University of Science and Technology, \\ Cumilla, Bangladesh \\ ${ }^{4}$ Department of Administrative Studies and Politics, University of Malaya, Kuala Lumpur, Malaysia
}

Article history:

Received: 18-03-2020

Revised: 03-06-2020

Accepted: 20-07-2020

Corresponding Author: Abdul Kadar Muhammad Masum

Department of Computer Science and Engineering, International Islamic University Chittagong, Chittagong, Bangladesh

Email: akmmasum@yahoo.com

\begin{abstract}
In this study, an integrated eVALUE model is introduced to examine the relationship between organizational performance and electronic Human Resource Management (eHRM) practice. The model also explored the drivers of electronic Human Resource Management (eHRM) practice in the organizations. The primary data collected by using a pilot survey and closed-ended questionnaire designed on Likert 7-point scale. Simple random sampling was adopted to yield 674 acceptable responses from 165 organizations in Bangladesh. The structural equation modeling results indicate that only six drivers out of nine namely senior executives' attitude, IT skill of HRM professionals, perceived compatibility, senior leadership support, firm culture and competitive pressure are revealed a strong positive effect on eHRM practice. The study revealed a positive and significant relationship between eHRM practice and organizational performance. Moreover, the effect of job satisfaction of HRM professionals is observed to partially mediate on practice performance relationship. The practical implication of the outcome of study and the extent of further research are postulates at the conclusion.
\end{abstract}

Keywords: Drivers, eHRM, Evolutionary Game Theory, HumanOrganization-Technology (HOT)-Fit Model, Job Satisfaction, Organizational Performance, Technology-Organization-Environment (TOE) Framework, Resource-Based View

\section{Introduction}

Electronic Human Resource Management (eHRM) combines Human Resource Management (HRM) and Information Technology (IT) in one platform. It is an interesting area with growing research attention in modern ages. But, IT setting in HRM research is unstructured and the scope of eHRM research is still micro level in context of developing nations, especially Bangladesh (Alam et al., 2016) and, latest research by (Quaosar et al., 2018) explores a similar result in Bangladesh. Moreover the eHRM field is yet continues as frantic and chaotic pace due to scanty of theoretical contributions (Strohmeier, 2007). Reviewing eHRM literature, it is seen that ample attention has provided on the eHRM pre-adoption stages such as "intent to adopt" (Ankrah and Sokro, 2016) and "eHRM adoption" (Bian, 2012; Teo et al., 2007) instead of the post-adoption issues such as "value creations" especially in developing nations. To this end, the current research seeks quantitative demonstration to absolutely comprehend the business importance of eHRM from the organizations of Bangladesh by ascertaining respondent's opinion on some selective drivers of eHRM practice and its impacts on Organization Performance (OP).

Bangladesh is an emerging country to adopt and adapt advanced technology. Beginning with manual HRM practices by most of the organizations in Bangladesh, recently, some firms are progressively moving towards technology based work process (Masum et al., 2015a). Besides, gradually achieving functional smoothness and minimizing cost of managing people at work, eHRM is highly drawing attention in Bangladesh (Masum, 2015). Research shows that the scope of eHRM is little wider in business houses of 
Bangladesh confining into few core areas namely, workforce recruitment and selection, employee training and payroll administrations (Chowdhury et al., 2013). The main obstacles for setting eHRM in the firms is scant of management concentration, nervous of incurring high investment, no experience and skill of practicing, the system compatibility, perceived advantages of eHRM (Bhuiyan and Rahman, 2014; Quaosar et al., 2018). Most papers incorporate applications of eHRM (Al Mamun and Islam, 2016; Khan et al., 2015), adoption and implementation barriers, complexity of eHRM and current status of eHRM application (Alam et al., 2016; Chowdhury et al., 2013; Quaosar et al., 2018). In pursuance of current study, the previous related papers were critically assessed. Moreover, scholars concluded the previous studies based on common descriptive statistics and did not use of latest inferential statistics. As such, it warrants that a quantitative study on eHRM is a doctrine of necessity and national issue at the primary stage of exploration in the context of Bangladesh (Jahan, 2014). Thus, methodical gap of previous research will be addressed in this study. Relevantly, few more raising issues of eHRM namely, the adoption or practice drivers, degree of association between eHRM and OP and rest other are also need to be examined.

This research is expected to satisfy the following objectives:

- To examine the most significant drivers of eHRM practice considering human, technological, organizational and environmental contexts

- To examine the relationship between eHRM practice and OP

- To investigate whether 'job satisfaction of HRM professionals' mediates the relationship of eHRM practice and $\mathrm{OP}$

In this study, a multi-dimensional eVALUE model is developed for the drivers that influence eHRM practice at organizational level. The model also can measure the effect of eHRM practice on firm's performance. The model includes potential variables i.e., senior executives' attitude and firm culture that are found missing in earlier eHRM research works. Empirical proof from this study suggests that these two variables are significant drivers for eHRM practice. Also, the most significant drivers are explored in context of a developing country Bangladesh. A positive impact of eHRM practice on OP (in HR practice) is revealed. Finally, the mediating effect of job satisfaction of HRM professionals is attested on eHRM practice and OP linkage.

The paper has several other parts. Section two describes research trend of eHRM in Bangladesh by reviewing the drivers of eHRM practice and its impact on OP based on TOE framework as well as HOT-fit model. List of hypotheses are also included in this section. The research model is presented in section three. Section four includes the methods and techniques of the study. Section five contains data analysis and detail interpretation discussion based on findings is shown section six and conclusion placed in section seven.

\section{Literature Review}

\section{Drivers of eHRM Practice at Organizational Level}

Empirical researches identified the growing importance of eHRM and for this reason some influential actors of eHRM adoption for different setting has recently explored (Bondarouk and Ruël, 2013). In this study, we scrutinized some drivers for eHRM practice. It is observed that mix of both quantitative and qualitative have applied in related research on IT setting. But, only two qualitative studies are found to be worth notable. The existing literature reveals that the influential drivers of eHRM adoption can be categorized into four contexts namely, human dimension, organization dimension, technology dimension and environmental dimension.

\section{Human Context}

The human context represents human dexterity and involvement to the IT operations (Masum et al., 2016a). This dimension consists of the matters lies with senior executives of the business likes Chief Information Officer (CIO) and Chief Executive Officer (CEO) and system end user- when the organizations engage in the setup of an innovative system. Based on the context, the study considered two variables of human dimension namely, senior executives' attitude and IT skill of HRM professionals to test.

According to the hierarchy, the senior executives are the key controller of a business firm who direct the new system set up and, they are generally owner of firms who empowered to make policy and propose procedure. A contemporary research revealed that high voltage knowhow of CEOs lessens the risk of impossibility of setting new IT systems (Masum et al., 2013). So, the knowledge of CEOs on work process and merits of electronic commerce (EC) applications stimulate them to take initiative of technology implementation (Ghobakhloo et al., 2011). Therefore, IT knowledgeable CEOs are comparatively more enthusiastic to set up IT at work (Alam et al., 2016). The authors opined that greater knowledge of CEOs will reduce the degree of uncertainty for adopting IS applications. In concordant with previous research, (Seif, 2015) also claimed that the IT knowledge and experience of CEOs has strong impacts on the decision of eHRM adoption in the business. Considering the above results, senior executives' attitude is assumed to be an important driver for this study. Oppositely, some studies denied the findings and stated that the senior executives' experience 
and IT attitude have insignificant impacts in the IT adoption decisions (Ahmadi et al., 2015; Lian et al., 2014). According to the discussion following hypothesis may design.

\section{H1: The Senior Executives' Attitude of an Organization Affects eHRM Practice}

IT expertise among the employees is also an important driver for the setup of latest technologies (Masum et al., 2018). Ample number of previous research strongly argued that IT skill of HRM professionals is a highly important element to expand of eHRM functions and keeping a consistent growth of the firm's performance (Bian, 2012; Teo et al., 2007). Because of insufficient IT experienced employees many firms' moves to their IT innovation very slowly (Ashraf et al., 2019). So, in small scale firms, if they have more knowledge in IT, it will help them to be more concentrated to accept the IT adoption at work (Gutierrez et al., 2015). But, IT research scholars found that employees' IT capability or prior experience is not a significant factor of technological system implementation in diverse settings (Al-Dmour, 2014; Low et al., 2011). Thus, a good size of previous studies revealed that IT skill of HRM professional play a significant role in IT adoption and reverse findings claimed by few quantitative approaches (Al-Mobaideen et al., 2013; Low et al., 2011). Based on above literature discussion, following hypothesis is proposed to examine eHRM practice at organizations in Bangladesh:

H2: The IT Skill of HRM Professionals of an Organization Affects eHRM Practice

\section{Technological Context}

This dimension explains the extent of befitting the inhouse and outside technology with functional structure of the organizations (Tornatzky et al., 1990). This context relates to the operationalization and potential realization of benefits and current organizational capabilities of adoption (Gutierrez et al., 2015). Relative advantage, perceived compatibility and perceived complexity are widely accepted drivers in the technological context.

The relative advantage of eHRM denotes the utility and efficiency generated from adoption of eHRM system in HRM department namely tasks automation, paperwork reduction and functional process innovation and communicate accurate, flawless HR information to the top level (Alam et al., 2016). Most of the previous research has attested that eHRM produced some common outcome in business firms namely, greater accuracy of work, the supply of real time and quickest HR information, optimize the cost (Bian, 2012; Masum et al., 2013). Similarly, one of the prime outcome of eHRM is to enabling the firms personnel in mapping strategy and make decision instead of micro level engagement of running routine HR functions (Low et al., 2011). Many researchers have found that relative advantage or perceived benefit as an important and commonly used variable to technology innovation adoption (Azhdari et al., 2019; Oliveira et al., 2014; Ramdani et al., 2013; Ghobakhloo et al., 2011). For this reason, (Teo et al., 2007) advocated that the relative advantages of eHRM for HRM professional and decision to adopt eHRM are positively correlated. Moreover, similar studies claimed that relative advantage is an essential element for eHRM practice in context of Jordanian firms (Al-Dmour, 2014) and Indonesian MSMEs (Imron et al., 2019). In contrast to that, some research discovered relative advantage is not a significant or important actor for eHRM adoption and implementation in Chinese firms (Al-Mobaideen et al., 2013; Bian, 2012). After analyzing the above related literatures following hypothesize may proposed:

H3: The Relative Advantage Perceived by an Organization Affects eHRM Practice

The perceived compatibility indicates the extent of reliability of technology among the users' present setting as well as work experience (Masum et al., 2015b). Similarly, the compatibility is connected with ensuring how much the technology and it techniques are conducive with holistic business strategy and needs of the organization (Ramdani et al., 2013). We have reviewed a good number of literatures on the same and extracted that compatibility is a dominant actor in IT innovation at work. For example, research of (Teo et al., 2007) on Singapore SMEs and (Imron et al., 2019) on Indonesian MSMEs claimed that compatibility largely dictate eHRM adoption decision. Likewise, compatibility is a highly considerable factor for EC application and eHRM adoption in business firms in many countries (Azhdari et al., 2019; Bian, 2012). But, later on some prominent researchers concluded reverse finding and opined that compatibility is not an important driver (Ahmadi et al., 2015; Gutierrez et al., 2015; Low et al., 2011). According to the discussion, following hypothesis is designed:

\section{H4: The Perceived Compatibility Affects eHRM Practice}

The perceived complexity is the assumed complexity among the user to use and understand the IT application (Ghobakhloo et al., 2011). Basically, the absence of IT expertise and technically soundness is the hindrance to adopt IT applications. This inability creates fear and thus resists the innovation (Al-Dmour, 2014). Research in UK (Gutierrez et al., 2015) and Jordan (Al-Dmour, 2014) claimed that perceived complexity is a significant factor of eHRM practice. In contrast to this, many researchers also found negative findings and explained that perceived complexity is not a significant factor at all 
to adopt eHRM decision in firms (Ramdani et al., 2013; Bian, 2012). Additionally, some scholars attested that perceived complexity is an insignificant driver of IT adoption at work (Imron et al., 2019; Ahmad et al., 2015; Low et al., 2011). According to the discussion, following hypothesis is designed:

\section{H5: The Perceived Complexity Affects eHRM Practice}

\section{Organizational Context}

The organizational dimension spelled about the environment of the firms that leads IT system innovation or make hindrances of same (Gutierrez et al., 2015). The present research considered two variables to explain the dimension and to test their impacts in eHRM practices namely, senior leadership support and firm culture.

The senior leadership support is explained the eagerness of the senior management hierarchy to grant and fund every types of resources to IT adoption in firms (Alam et al., 2016). Besides, the senior leadership support is a yardstick to leverage the employee knowledge on IT applications to gather financial resources, infrastructure and competency of employees (Bian, 2012). Prior studies in similar fields extracted and reach in the common consensus that senior leadership support is a strong denominator for IT adoption successfully (Imron et al., 2019; Lian et al., 2014; Sila, 2013; Bian, 2012; Teo et al., 2009; 2007). Unlikely, (Ahmadi et al., 2015; Gutierrez et al. (2015) and (Al-Mobaideen et al., 2013) explored that senior leadership support is an insignificant driver for implementation of IT applications. Based on above literature discussion, following hypothesis is proposed to examine eHRM practice at organizations in Bangladesh:

\section{H6: The Senior Leadership Support of an Organization} Affects eHRM Practice

Firm culture denotes the common values and beliefs, customs of the people at organizations and shared attitudes, (Teo et al., 2009). Predecessor researcher recommended the culture is one of key elements IT adoption at functional work of the firms (Al-Dmour, 2014; Jackson, 2011). A change favored organization always welcome the positive changes in the organization, for this reason, the research of (Panayotopoulou et al., 2007; Indeje and Zheng, 2010) claimed that if the organization have the attitude of change mindset can easily accept and implement the IT system in functional work places that in turn generate firms performance in a set standard. Other research contested that firm culture neither really a significant actor nor an important differentiator between adopters and non-adopters of new IT adoption (Alkhater et al.,
2018; Teo et al., 2009). After analyzing the above related literatures following hypothesize may proposed:

\section{H7: The Firm Culture Affects eHRM Practice.}

\section{Environmental Context}

Environmental dimension broadly talk about external factors. Under this context, the environmental drivers influence IT adoption in firms (Ramdani et al., 2013). Ample scientific research recognized environmental actors as a highly influential as that of organizational and technological factors (Ghobakhloo et al., 2011). In this study, two variables namely, competitive pressure and state patronization under environmental context are included to investigate their impact on eHRM practice based on past IT adoption literature.

Competitive pressure denotes the fear of the organization to lose the competitive strength in the industry footing and, this fear is derived due to nonadoption of innovation technology (Oliveira et al., 2014). Thus, it explained the degree of competitive pressure waved from the rivals of the industry in the grounds of technology adoption as well as the firm's strength over it (Ramdani et al., 2013). Moreover, (Gutierrez et al., 2015) stated that the threat of competition is highly influence the adoption of IT application. Based on similar research in Chinese firms by (Bian, 2012), authors explored that competitive pressure is a highly significant elements of eHRM adoption. With that same train of thought, many quantitative researches resulted the competitive pressure as an important driver for any IT innovation adoption (Al-Dmour, 2014; Ramdani et al., 2013; Ghobakhloo et al., 2011; Al-Qirim, 2007), while some researchers opposed its significance in IT adoption (Ahmadi et al., 2015; Oliveira et al., 2014; Aboelmaged, 2014; Lian et al., 2014; Teo et al., 2007). Thus, following hypothesize can be drawn from the above discussion.

\section{H8: The Competitive Pressure Affects eHRM Practice}

The state patronization for IT adoption is a macro setup that consists of multiple role of the government of the country. In particular, the state patronization consist of government vision and rules to promote IT adoption, IT training, IT workshops, tax incentives and subsidies, facilitating quality public IT infrastructure, provision of information, state control of privacy and security of information, laws to protect cybercrime and many other related patronizations (Zhu and Kraemer, 2005). Al-Dmour (2014) claimed that the government regulation is an important predictor to adopt eHRM practices. In the same vein, (Zhu and Kraemer, 2005) explored that that the support from public regulatory body of the state is a significant tool to navigate ebusiness in Europe. Some latest research conducted by 
(Oliveira et al., 2014; Ahmadi et al., 2015) attested that there is a reverse relation between government policy and IT practice at work and the relation is quite visible in the health sector. Some scholars contested that the state patronization is not always significant components for new IT adoption in business firms (Lian et al., 2014; Oliveira et al., 2014). According to above discussion, we proposed following two hypotheses for the eHRM practice.

\section{H9: The State Patronization for an Organization Affects eHRM Practice}

\section{Value Creation of eHRM and $O P$}

Eminent research scholar in the field of eHRM (Bondarouk and Ruël, 2013) reports the three tiers of eHRM practices in enterprises namely, personal, the organizational and the society. This study underscored eHRM practice and its value generating at the firms perceiving that eHRM practices can be value additive only if it can excel the first hand HR support to the stakeholders. A cross country study of (Parry, 2011) advocated that eHRM practices helps HRM department to optimize the functional value of the firms and no impact on cost due to HR manpower reduction. For this ground, the study recommended firms to practice eHRM to divert the concentration of HRM professionals towards the strategic value additive task instead of routine transaction tasks. Whereas, (Škudienè et al., 2020) claimed that eHRM has transformed organizational work process to technology, lessen the administrative burden and reduce the cost. Research of (Ruël and Van der Kaap, 2012) attested the role of eHRM practice significantly lead to optimize the work efficiency and effectiveness of HRM department. The explorative driver analysis was used to identify the three contexts (effectiveness, efficiency and HR service quality). On the contrary, (Marler and Fisher, 2013) reviewed 40 research papers related to the eHRM applications and OP from 1999 to 2011 and extracted no significant relationships between the constructs. Moreover, there is still scanty of eHRM related research and its effects on OP. Following hypothesize can be drawn from the above discussion:

\section{H10: eHRM Practice Affects OP}

\section{Job Satisfaction, eHRM Practice and OP}

The supremacy of eHRM implementation is its direct influence on employee productivity. Research claimed that employees consider eHRM as a change agent of work process in the job and navigate them to be satisfied to the job in the pre and post implementation (Marler and Fisher, 2013). But, the level of satisfaction may continuously decline if there is difficulty of uses (Beckers and Bsat, 2002). So, the cause of satisfaction in one's job is multifaceted where attitude to the job is worth notable. In reality, job environment is the nucleus of job satisfaction (Masum et al., 2016b). Job situation defines job satisfaction. Consequently, if job situation is positive employee feel satisfied and vice-versa (Masum et al., 2015a). This paper reflected the role of eHRM as a technological tool to leads employee satisfaction at work. Thus, our next hypothesis is.

\section{HA11 (a): eHRM Practice Influence Job Satisfaction of HRM Professionals}

No organization can even think of a sustainable survival in the market in presence of employee job dissatisfaction. There is a chain effect between the relationship of employee satisfaction and OP where the former leads the later one. Previous research discovered the significant influence of eHRM adoption on employee task satisfaction and intention to quite (Maier et al., 2013). The transformation of technology from traditional to manual work process has become the demand of taking breadth in fierce-competitive market and for this reason; research on employee satisfaction while technology adoption is becomes a necessity. Distinguished researcher advocated that the employee satisfaction and feeling of comfort at work stimulate a high extent of OP. Employee satisfaction is like the oxygen of survival for organizational productivity. A contemporary research inspected employee job satisfaction for using information system (Chang et al., 2012). They unveiled that employee satisfaction in technology adoption has strong effect in their work outcome and professional commitments. Similar research at the organizational level concluded that task satisfaction of employee positively influence the firms total performance (Shiu and $\mathrm{Yu}, 2010)$. So following research hypothesis is proposed:

H11 (b): Job Satisfaction of HRM Professionals has Significant Effect on $O P$

Grounded on HA11 (a) and HA11 (b), it was to test the mediating influence of job satisfaction of HRM professionals on the relationship of eHRM practice and OP. Based on above discussion, we develop the below hypothesis.

H11: Job Satisfaction of HRM Professionals Acts as the Mediator Between the Association of eHRM Practice and $O P$

\section{Research Model}

Despite the eHRM system is gradually a source of concentration among scholars and professional practitioners, the literature on eHRM is yet uneven and not clears specifically on eHRM practice and the value generation through it. Literature suggests a gap of integrated theoretical framework. Initially, (Zhu and Kraemer, 2005) tried to develop a combined, multi-dimensional framework 
of employing e-business at work and ascertaining the value with the integration of TOE framework (Tornatzky et al., 1990) and RBV theory (Penrose, 2009).

From a thorough review of the existing literature, a significant gap of research on drivers of eHRM practice and impact of eHRM on OP is revealed. Based on rigorous literature review, nine drivers i.e., senior executives' attitude, IT skill of HRM professionals, perceived compatibility, perceived complexity, senior leadership support, firm culture, competitive pressure and state patronization to eHRM practice at organizational level are classified into four contexts i.e., human, technology, organization and environment. In present research, the impact of eHRM practice on OP is tested. The measurement attributes of OP are considered some nonfinancial indicators as a multi-dimensional performance measurement tool. OP was measured by means of the six indicators: efficiency, effectiveness, development, satisfaction, innovation and quality. Finally, this study includes mediator variable (Job Satisfaction of HRM professionals) to test whether its inclusion could change the solid association between eHRM practice and OP.

The blend of (Zhu and Kraemer, 2005) model with the improvements lead to the development of integrated, an interactive and multi-dimensional framework known as eVALUE model to further investigate the effect of eHRM practice on OP. Grounded on the assessment of past empirical papers, the present study propose an eVALUE Model Fig. 1 integrating TOE model (Tornatzky et al., 1990), HOT-fit model (Yusof et al., 2008), ResourceBased View (RBV) (Penrose, 2009), Technology Acceptance Model (TAM) (Davis, 1989) and evolutionary game theory (Kauffman et al., 2002) in proposing multi-dimensional theoretical model. Based on RBV the technology innovation is considered as the distinct resources to win competitive advantage in the market and, the argument of TAM in the research is to fit the derived benefit from the perceived uses of new system as well as acceptability. Besides, the argument of evolutionary game theory employed to fit the e-application of business as strategic choice that is linked with TOE model (industry, firms and e-business characters). Thus, the proposed framework tries to support existing theories. Moreover, this research claim to be the premier in light of eHRM practice drivers at organizational level from of HR managers' viewpoint evaluating the firm's value derived from the eHRM applications.

\section{Research Methods}

\section{Sampling Procedures and Data Collection}

The target population of this study is organizations in Bangladesh those have already implemented eHRM systems. An "eHRM system using organization" is defined as one which has implemented at least four eHRM system modules. There is no official source to obtaining numerical data on the numbers of eHRM implemented firms and for this reason, multiple sources, platforms have been uses to make a total list of companies who furnishes eHRM practice (Dezdar, 2011). Finally, 165 firms (manufacturing and service industry) are identified for respondent selection. A total of 900 questionnaires dropped to HR managers of selected organizations. The useable questionnaires were 674 with the response rate $74.89 \%$ applying random sampling technique. The questionnaires are distributed to 3-level managers namely, lower level, mid-level and upper level from HR division who have a minimum of 3 years' service story with the sample organization. The pre-tested questionnaire is based on Likert 7point scale and close-ended.

Armstrong and Overton (1977) extrapolation procedure is adopted to confirm the absence of nonresponse bias. The result of t-test (independent sample) revealed that there no differences in pre-post response ( $p$ $=0.16$ and 0.27 , respectively). Additionally, a list 50 person from non-respondents are randomly targeted and sent a detailed version of the questionnaire ensuring necessary monitoring to obtain completed questionnaire. Accordingly, t-test employed to measure the comparative outcome of survey and no significant deviation are visible ( $p=0.17$ and 0.14 , respectively). Thus, the research confirms no bias of non-response.

\section{Development of Research Instrument}

\section{Questionnaire Reliability}

The questionnaire consists of two segments. Segment one is arranged with demographic information of respondents and firms. Whereas, segment two is equipped with core issues of research like the current status of the eHRM user organizations and the selected nine drivers to eHRM practice. All the responses are coded into 7-point Likert scale. At the beginning, the draft questionnaire was submitted to the academic and professionals experts to confirm the validity and reliability where five from academics and five from HRM senior professionals of the same field of organizations (Cooper et al., 2003). Based on the suggestion from the experts some reviews were incorporated. In this study, reliability is measured by the value of Cronbach's Alpha $(\alpha)$ which is required to achieve a level of greater than 0.7 for the items of the variables to be accepted as reliable (Hair et al., 2010).

\section{Measurement of Variables}

There are nine variables extracted from previous literatures. Table 1 exhibites the details about measurement variables and those are placed below. 
Table 1: Measurement of variables

\begin{tabular}{|c|c|c|c|c|}
\hline Serial & Variables & Meaning & Scale items & Sources \\
\hline 1 & $\begin{array}{l}\text { Senior executives' } \\
\text { attitude }\end{array}$ & $\begin{array}{l}\text { Delineated the desire and attitude of senior executives } \\
\text { to set up work innovation, experiment the innovation } \\
\text { through supportive system and finally their extent of } \\
\text { morality to new system. }\end{array}$ & 5 & $\begin{array}{l}\text { Thong and Yap (1995), } \\
\text { Lian et al. (2014). }\end{array}$ \\
\hline 2 & $\begin{array}{l}\text { IT skill of HRM } \\
\text { professionals }\end{array}$ & $\begin{array}{l}\text { Represents the required IT functional skill possessed } \\
\text { by the HRM professionals }\end{array}$ & 5 & $\begin{array}{l}\text { Kuan and Chau (2001), } \\
\text { Teo et al. (2007). }\end{array}$ \\
\hline 3 & Relative advantage & $\begin{array}{l}\text { The scope of obtaining functional advantages by the } \\
\text { user employee upon adoption of IT at work place. }\end{array}$ & 7 & $\begin{array}{l}\text { Moore and Benbasat (1991), } \\
\text { Ghobakhloo et al. (2011), } \\
\text { Teo et al. (2007), } \\
\text { Premkumar } \text { et al. (1999). }\end{array}$ \\
\hline 4 & Perceived compatibility & $\begin{array}{l}\text { Explained the extent to which the adopted technology } \\
\text { is aligned with firms' physical structure, accommodated } \\
\text { with experience and capacities of potential users. }\end{array}$ & 5 & $\begin{array}{l}\text { Teo et al. (2007), } \\
\text { Premkumar et al. (1999) }\end{array}$ \\
\hline 5 & Perceived complexity & $\begin{array}{l}\text { represents the assumed complexities and hurdles to use } \\
\text { the IT adoption }\end{array}$ & 4 & $\begin{array}{l}\text { Premkumar et al. (1999), } \\
\text { Teo et al. (2007) Alam et al. }\end{array}$ \\
\hline 6 & $\begin{array}{l}\text { Senior leadership } \\
\text { Supports }\end{array}$ & $\begin{array}{l}\text { Defined the readiness of conducive organizational } \\
\text { environment for eHRM through advent of all } \\
\text { required resources }\end{array}$ & 5 & $\begin{array}{l}\text { (2016), Teo et al. (2007) and } \\
\text { Premkumar } \text { et al. (1999). }\end{array}$ \\
\hline 7 & Firm culture & $\begin{array}{l}\text { The culture of firms denotes a set of actors namely } \\
\text { employee beliefs, norms, shared experience and } \\
\text { management philosophies towards IT adoption at work. }\end{array}$ & 5 & $\begin{array}{l}\text { Hofstede (2001), Matrin and } \\
\text { Terblance (2003), } \\
\text { Krumbholz and Maiden (2001). }\end{array}$ \\
\hline 8 & Competitive pressure & $\begin{array}{l}\text { Refers the industry pressure generated from fierce } \\
\text { competition which stimulates the firms to incorporate } \\
\text { new technology to win the competitive advantages. }\end{array}$ & 5 & $\begin{array}{l}\text { Premkumar } \text { et al. (1999), } \\
\text { Teo } \text { et al. }(2007) \text {, (Masum } \\
\text { et al. }(2015 \mathrm{a} ; 2015 \mathrm{~b} ; 2015 \mathrm{c}) \text {. }\end{array}$ \\
\hline 9 & State Patronization & $\begin{array}{l}\text { Explains the extent to which the government of the country } \\
\text { formulates rules and regulations, providing financial and } \\
\text { non-financial resources to adoption of IT at the organization }\end{array}$ & & $\begin{array}{l}\text { Kuan and Chau (2001), } \\
\text { Alam et al. (2016), } \\
\text { Al-Dmour (2014) }\end{array}$ \\
\hline
\end{tabular}

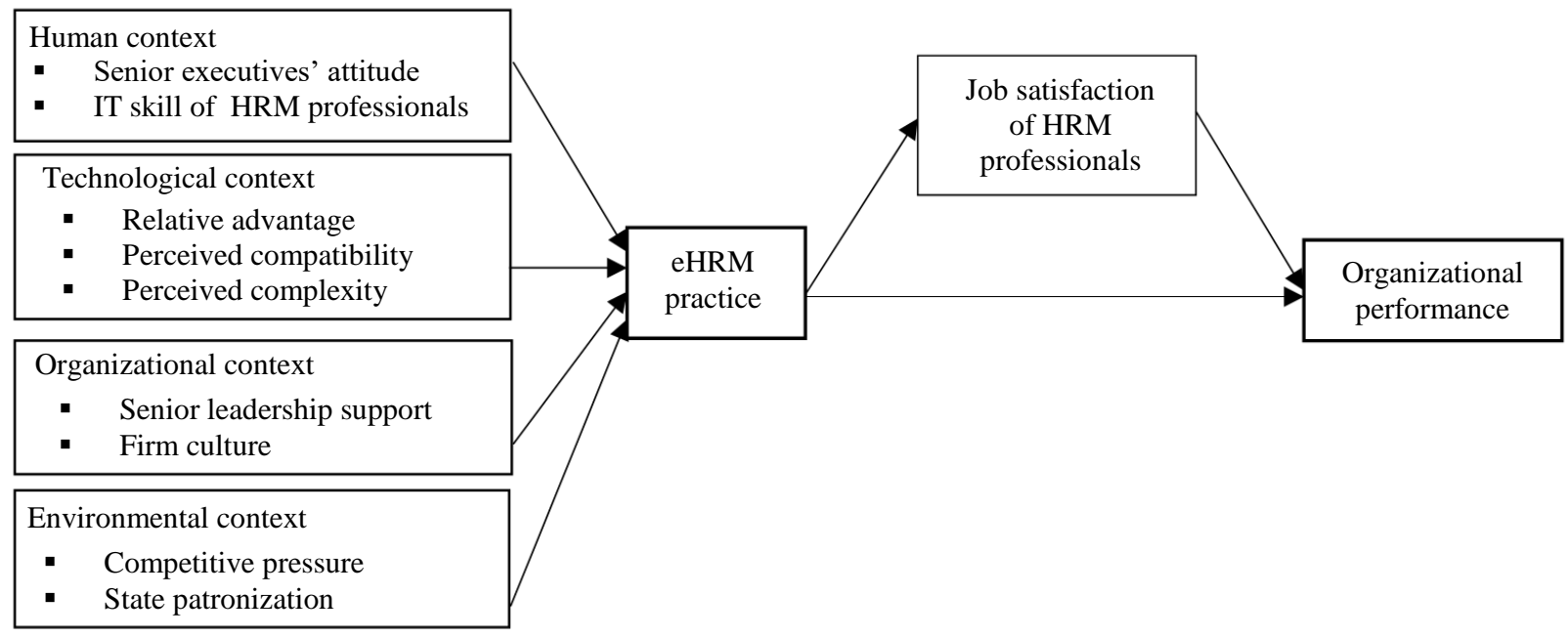

Fig. 1: Research model

Lastly, the intervening variable (eHRM practice) is tested based on the perception of respondent on the degree of its applications at work. In this research the measurement scale of intervening variable has developed from prior research of (Al-Dmour, 2014). Therefore the seven mainstream HRM functional modules namely, employee recruitment and selection, employee training, salary and payroll management, compensation and benefits, assessment of performance, workforce planning and communication module are considered. The dependent variable of the research is OP which was examined using the scale developed by (Katou and Budhwar, 2006). Besides, OP was measured by six non-financial indicators: Efficiency, effectiveness, development, satisfaction, innovation and quality. The job satisfaction of HRM professionals is mediating variable that is examined by applying the scale used by (Maier et al., 2013). 


\section{Analysis and Results}

\section{Descriptive Statistics of Respondents}

The study surveyed two segment of industry such as service and manufacturing and the sample from service related firms is higher $(56.97 \%)$ than manufacturing $(43.03 \%)$. Analyzing the respondent age group, there are $48.22 \%$ of employees who belong to the age of 40 years. The minimum education level is graduation completed $(76.56 \%)$ and service history is not less than five years and onwards $(64.39 \%)$. In terms of hierarchy level of respondents there are $(18.55 \%)$ from top level and the maximum number of respondents $(47.03 \%)$ are lower level manager from HR division. Notably, we have accepted this group of responded because of their mastering knowledge of business and operational work process, embedded with high voltage attire with mainstream function and business environment for a long time that aspires to be produced reliable output of the research.

\section{Multivariate Assumptions and Scale Purification}

After data were cleaned and errors corrected, the data were assessed for outliers' linearity, homoscedasticity, multicollinearity, normality and common method bias. In this study, suitable technique i.e. single-factor test was carried out for evaluating whether common method bias is a serious issue. In this respect, Exploratory Factor Analysis (EFA) was conducted for all variables in the research (Hair et al., 2010). The results of this test for all constructs demonstrated one factor and no single factor emerged from the unrotated factor solution and accounted for the majority of the variance among variables. In this study, the results of scale purification shows no item was found to have itemtotal-correlation below the cut-off point of 0.5 (Hair et al., 2010). Moreover, an EFA was conducted on the independent variables for items re-confirmation.

\section{Exploratory Factor Analysis (EFA)}

The Exploratory Factor Analysis (EFA) was executed for nine predictor variables Table 2 and one moderating variable Table 3. SPSS, version 20 was used to run the relevant statistical tests. EFA with varimax rotation was applies to determine the convergent validity and dimensionality of the association between scale items and variables. But the research didn't employed EFA for dependent variable by dint of visible differences among selected issues of non-nonfinancial variables. Each of the HRM functions considered in the study is not fall in equal scope and for this reason; EFA is not employed for the intervening construct - eHRM practices. According to the suggestion of (Hair et al., 2010), few items were discarded in the ground of lower Cronbach's alpha $(\alpha)$ values and lower loading value (lower than 0.5 ). In this study, the construct reliability is assessed by Cronbach's alpha. All the Cronbach's alpha values of nine construct are greater than 0.70 , therefore the constructs are considered to be reliable (Nunnally, 2010). These nine factors explain $75.34 \%$ of the variance. In EFA, the results specify the Barlett Test of Sphericity (Bartlett, 1954) satisfied statistical significance (Chi-Square = $19986.567, p<0.01)$ and the Kaiser-Meyer-Oklin (KMO) tested the sampling adequacy which scored 0.958 , higher than the guidelines value of.60 factor analysis (Pallant, 2011).

EFA was conducted on this mediating variable (Job satisfaction of HRM professional). The factor loading matrix shows that with Eigen value of more than 1, one factor emerges. This single factor explains $73.43 \%$ of the variance. The results specify the Barlett test of sphericity (Bartlett, 1954) met statistical significance (Chi-Square $=1123.231, p<0.01)$ and the KMO measure of sampling adequacy was 0.821 , greater than the recommended value of 0.60 (Pallant, 2011).

\section{Confirmatory Factor Analysis (CFA)}

The study employed Structural Equation Modeling (SEM) to examine the models proposed in Fig. 1 and 2. There are 4 stages of analysis such as stage 1 investigates the assumption of multivariate analysis, stage 2 is the analysis of exploratory drivers with varimax rotation, stage 3 examined the model and stage 4 examined the structural framework. Based on the prescriptions of (Hair et al., 2010), the sample size is higher than 300 which adequate fit the SEM. The normal distribution of data confirmed through the value of skewness and kurtosis that scored within the considerable magnitude (Hair et al., 2010). Besides, the values of correlation coefficient of independent construct lower than 0.80 is the indicator of non multicollinearity. Thus, the assumptions of multivariate analysis are not biased (Pallant, 2011).

According to (Hair et al., 2010), a two ways techniques can be used to assess the validity of measurement framework namely, separate testing every variable and group testing at a time. And, the model fit can be assessed based on applying 3 to 4 fit indices (Hair et al., 2010) and thus we have applied the $x^{2}\left(\right.$ the $\mathrm{x}^{2}$ ratio to the degree of freedom), the value of Comparative Fit Index (CFI), the Goodness-of-Fit Index (GFI) and the Root Mean Square Error of Approximation (RMSEA). The result of analysis shows the value of CFI and GFI is higher than 0.9 which attested the acceptability of the model fit. Besides, the RMSEA value of each variable is less than 0.08 . For $x^{2}$, the desired level lower optimum of 3 for each nine variables of the study Table 4 . Moreover, the overall fit indices for the measurement model along with all constructs involve normed $\mathrm{x}^{2}=1.865$; $\mathrm{CFI}=0.971 ; \mathrm{GFI}=0.952$ and RMSEA $=0.037$. Therefore it can be confirmed that there is unidimensionality in the construct. The detail of each construct is summarized in Table 4. 
Abdul Kadar Muhammad Masum et al. / Journal of Computer Science 2020, 16 (7): 983.1000 DOI: $10.3844 /$ jessp.2020.983.1000

Table 2: EFA of independent variables

\begin{tabular}{|c|c|c|c|c|c|c|c|c|c|}
\hline \multirow[b]{2}{*}{ Items } & \multicolumn{9}{|l|}{ Factors } \\
\hline & 1 & 2 & 3 & 4 & 5 & 6 & 7 & 8 & 9 \\
\hline$\overline{\mathrm{RA} 1}$ & 0.812 & & & & & & & & \\
\hline RA3 & 0.773 & & & & & & & & \\
\hline RA7 & 0.712 & & & & & & & & \\
\hline RA4 & 0.701 & & & & & & & & \\
\hline RA2 & 0.689 & & & & & & & & \\
\hline RA6 & 0.677 & & & & & & & & \\
\hline RA5 & 0.610 & & & & & & & & \\
\hline $\mathrm{CO} 3$ & & 0.741 & & & & & & & \\
\hline $\mathrm{CO} 1$ & & 0.740 & & & & & & & \\
\hline $\mathrm{CO} 5$ & & 0.727 & & & & & & & \\
\hline $\mathrm{CO} 4$ & & 0.694 & & & & & & & \\
\hline $\mathrm{CO} 2$ & & 0.579 & & & & & & & \\
\hline OC5 & & & 0.801 & & & & & & \\
\hline $\mathrm{OC} 2$ & & & 0.785 & & & & & & \\
\hline OC4 & & & 0.760 & & & & & & \\
\hline OC3 & & & 0.738 & & & & & & \\
\hline $\mathrm{OC} 1$ & & & 0.601 & & & & & & \\
\hline $\mathrm{CP} 1$ & & & & 0.715 & & & & & \\
\hline CP3 & & & & 0.710 & & & & & \\
\hline CP5 & & & & 0.691 & & & & & \\
\hline $\mathrm{CP} 4$ & & & & 0.684 & & & & & \\
\hline $\mathrm{CP} 2$ & & & & 0.594 & & & & & \\
\hline TM5 & & & & & 0.740 & & & & \\
\hline TM2 & & & & & 0.727 & & & & \\
\hline TM3 & & & & & 0.694 & & & & \\
\hline TM1 & & & & & 0.640 & & & & \\
\hline TM4 & & & & & 0.612 & & & & \\
\hline $\mathrm{EC} 1$ & & & & & & 0.846 & & & \\
\hline EC3 & & & & & & 0.754 & & & \\
\hline EC2 & & & & & & 0.689 & & & \\
\hline EC4 & & & & & & 0.661 & & & \\
\hline $\mathrm{CX} 4$ & & & & & & & 0.891 & & \\
\hline CX1 & & & & & & & 0.871 & & \\
\hline $\mathrm{CX} 2$ & & & & & & & 0.799 & & \\
\hline $\mathrm{CX} 3$ & & & & & & & 0.748 & & \\
\hline SE5 & & & & & & & & 0.871 & \\
\hline SE3 & & & & & & & & 0.815 & \\
\hline SE2 & & & & & & & & 0.780 & \\
\hline SE1 & & & & & & & & 0.738 & \\
\hline SE4 & & & & & & & & 0.653 & \\
\hline VS1 & & & & & & & & & 0.813 \\
\hline VS2 & & & & & & & & & 0.733 \\
\hline VS4 & & & & & & & & & 0.677 \\
\hline VS5 & & & & & & & & & 0.612 \\
\hline VS3 & & & & & & & & & 0.556 \\
\hline$\%$ of variance & 37.267 & 6.934 & 6.344 & 5.62 & 5.241 & 4.503 & 4.205 & 3.715 & 2.581 \\
\hline Eigen value & 20.195 & 4.118 & 3.806 & 3.422 & 3.221 & 2.83 & 2.672 & 1.412 & 1.341 \\
\hline
\end{tabular}

Total variance extracted by 11 factors $=75.34 \%$

Table 3: EFA of mediating variable

\begin{tabular}{lcc}
\hline Items & Communalities extraction & Factor 1 \\
\hline JS4 & 0.776 & 0.923 \\
JS1 & 0.883 & 0.887 \\
JS3 & 0.812 & 0.856 \\
JS2 & 0.798 & 0.812 \\
\% of variance & 73.43 & \\
Eigen value & 3.09 & \\
\hline
\end{tabular}


Table 4: Summery of model reliability and validity

\begin{tabular}{|c|c|c|c|c|c|c|c|c|c|}
\hline Variables & Cronbach's alpha $(\alpha)$ & CFI & GFI & RMSEA & $x^{2}$ & $\mathrm{CR}$ & AVE & MSV & ASV \\
\hline Senior Executives' attitude (SEC) & 0.89 & 0.999 & 0.995 & 0.017 & 1.217 & 0.863 & 0.720 & 0.320 & 0.145 \\
\hline IT skill of HRM Professionals (TC) & 0.92 & 0.996 & 0.963 & 0.055 & 2.45 & 0.861 & 0.642 & 0.236 & 0.168 \\
\hline Relative Advantage (RA) & 0.88 & 0.967 & 0.962 & 0.043 & 1.343 & 0.867 & 0.720 & 0.425 & 0.102 \\
\hline Perceived Compatibility (COM) & 0.84 & 0.997 & 0.982 & 0.023 & 2.031 & 0.912 & 0.687 & 0.263 & 0.153 \\
\hline Perceived Complexity (CX) & 0.91 & 0.982 & 0.979 & 0.041 & 2.201 & 0.919 & 0.641 & 0.352 & 0.244 \\
\hline Senior leadership support(TM) & 0.90 & 0.979 & 0.975 & 0.023 & 2.101 & 0.875 & 0.683 & 0.523 & 0.264 \\
\hline Firm culture (OC) & 0.85 & 0.969 & 0.963 & 0.034 & 1.151 & 0.869 & 0.634 & 0.490 & 0.412 \\
\hline State patronization (GS) & 0.86 & 0.998 & 0.988 & 0.035 & 1.513 & 0.891 & 0.687 & 0.458 & 0.478 \\
\hline eHRM practice (EHR) & 0.83 & 0.997 & 0.987 & 0.028 & 1.346 & 0.932 & 0.645 & 0.253 & 0.164 \\
\hline Organizational Performance (OP) & 0.91 & 0.995 & 0.982 & 0.012 & 1.203 & 0.916 & 0.570 & 0.461 & 0.346 \\
\hline
\end{tabular}

In the study, the construct validity and reliability also measured Table 4. Therefore, convergent validity was employed to determine construct validity and, discriminant validity of all items confirms by the analysis of Maximum Shared Squared Variance (MSV) and Average Shared Squared Variance (ASV) as the value is lower than Average Variance Extracted (AVE) (Hair et al., 2010). To this end, the convergent validity determined by the adoption of composite Reliability (CR) as the value of each variable is higher than AVE. Essentially, the value of AVE for each construct is higher than 0.5 that confirm the validity of 11 items. Furthermore, the CR of every construct items is higher than 0.7 and factor loading value is higher than threshold level 0.5 which certifies the unidimensionality of the constructs and reliability of the measures (Hair et al., 2010).

\section{Structural Equation Modeling Analysis Results}

In structural model 1, nine independent variables (senior executives' attitude, IT skills of HRM professionals, relative advantage, perceived compatibility, perceived complexity, senior leadership support, firm culture, competitive pressure and state patronization), intervening variable (eHRM practice), dependent variable (OP) and intermediary (job satisfaction of HRM Professionals) are combined into a single model Fig. 2 to test the relationship among the variables. The SEM fit indices shows that the designed model of study is living in a tolerable fit. The value of RMSEA (0.044) is less than accepted limit of 0.08 . Besides, the value of CFI and GFI are 0.945 and 0.933 respectively that is more than the proposed standard value of 0.90 . Also, the $x^{2}$ is counted for 1.734 that is less than the proposed standard value (should be less than 3 ). Thus, developed model is considered as a good fit.

We found in analyses of structural model 2 Fig. 3, consists of all variables except intermediary (job satisfaction of HRM professionals). Based on the results of the SEM fit indices, the proposed model presents an acceptable fit. The value of RMSEA (0.042) is less than proposed standard limit of 0.08 and going forward CFI (0.932) and GFI (0.912) was higher than standard limit of 0.90 . Additionally, $x^{2}$ produced the value 1.23 was less than standard limit (should be less than 3). Finally, the summery of structured model value is the authentic reflection of complete fit.
In addition, the $R^{2}$ for eHRM practice is $77.9 \%$ mean that all the predictor constructs claimed about $78 \%$ of the inequality explained in eHRM. On the other hand, the $\mathrm{R}^{2}$ for OP is $63.8 \%$ shows that the sum total of variables employed in the study claimed about $64 \%$ of the inequality explained in OP.

\section{Hypotheses Testing Results}

Based on structural model 1 Fig. 2, it is evident that a significant association prevailed among six variables (out of $9)$ and eHRM practice. These six variables are senior executives' attitude $(\beta=0.515, p<0.001)$, IT skill of HRM professionals $(\beta=0.341, p<0.001)$, perceived compatibility $(\beta=0.122, p<0.01)$, senior leadership support $\mathrm{t}(\beta=0.319$, $p<0.001)$, firm culture $(\beta=0.141, p<0.01)$ and competitive pressure $(\beta=0.152, p=0.341)$. So, the finding of this study accepts the proposed hypotheses $(\mathrm{H} 1, \mathrm{H} 2, \mathrm{H} 4, \mathrm{H} 6, \mathrm{H} 7$ and H8). However, relative advantage $(\beta=0.057, p=0.251)$, perceived complexity $(\beta=0.082, p=0.253)$ and state patronization $(\beta=0.057, p=0.342)$ are found to have no significant relationship with eHRM practice. Therefore, the result of the research rejects the proposed hypotheses $(\mathrm{H} 3$, $\mathrm{H} 5$ and H9). Besides, the result evident there is a strong positive association prevails between eHRM practice and OP $(\beta=0.310, p<0.001)$. Therefore, the H10 is accepted. Moreover, eHRM practice is shows a strong association with the task satisfaction of HRM professionals $(\beta=0.763$, $p<0.001)$. However, eHRM practice is also found to have a significant relationship with task satisfaction of HRM professionals $(\beta=0.289, p<0.001)$ in structural model 2 . Finally, job satisfaction of HRM professionals is evident a strong positive association with OP $(\beta=0.454, p<0.001)$. As such, $\mathrm{H} 11 \mathrm{a}$ and $\mathrm{H} 11 \mathrm{~b}$ are accepted.

In view to examine the mediating effect of job satisfaction of HRM professionals (JS), we have compared the structural model 1 and 2. Therefore, the direct and indirect relationship among the predictor constructs (eHRM practice) and the exploratory variable - OP are analyzed. Structural model 2 Fig. 3 indicates beta estimate $(\beta)$ of eHRM practice and OP is decreased as 0.289 though we found the $p$-value $(0.0000$ is significant). Thus, we have experienced a partial mediation in the study. Considering the inclusion of moderating variable - JS into the model 1 and reduction of beta estimate still shows the eHRM 
practice has significant effect on OP. So, we finalized that eHRM practice has significant direct impact on OP and further significant indirect impact on OP in presence of the mediating variable - job satisfaction of HRM Professionals. As such, $\mathrm{H} 11$ is only partially supported.

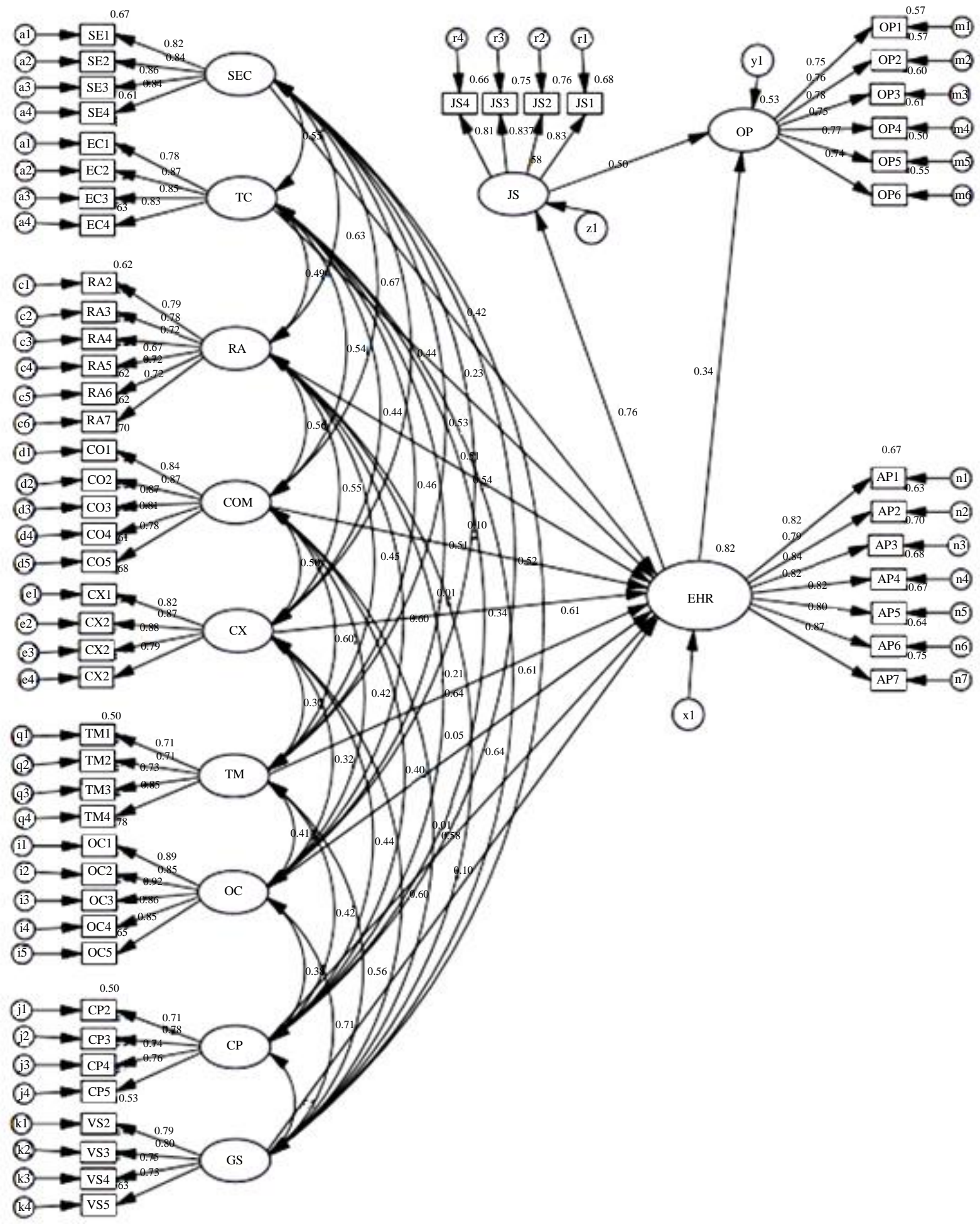

Fig. 2: Structural Model 1 of proposed eVALUE Model for eHRM practice 

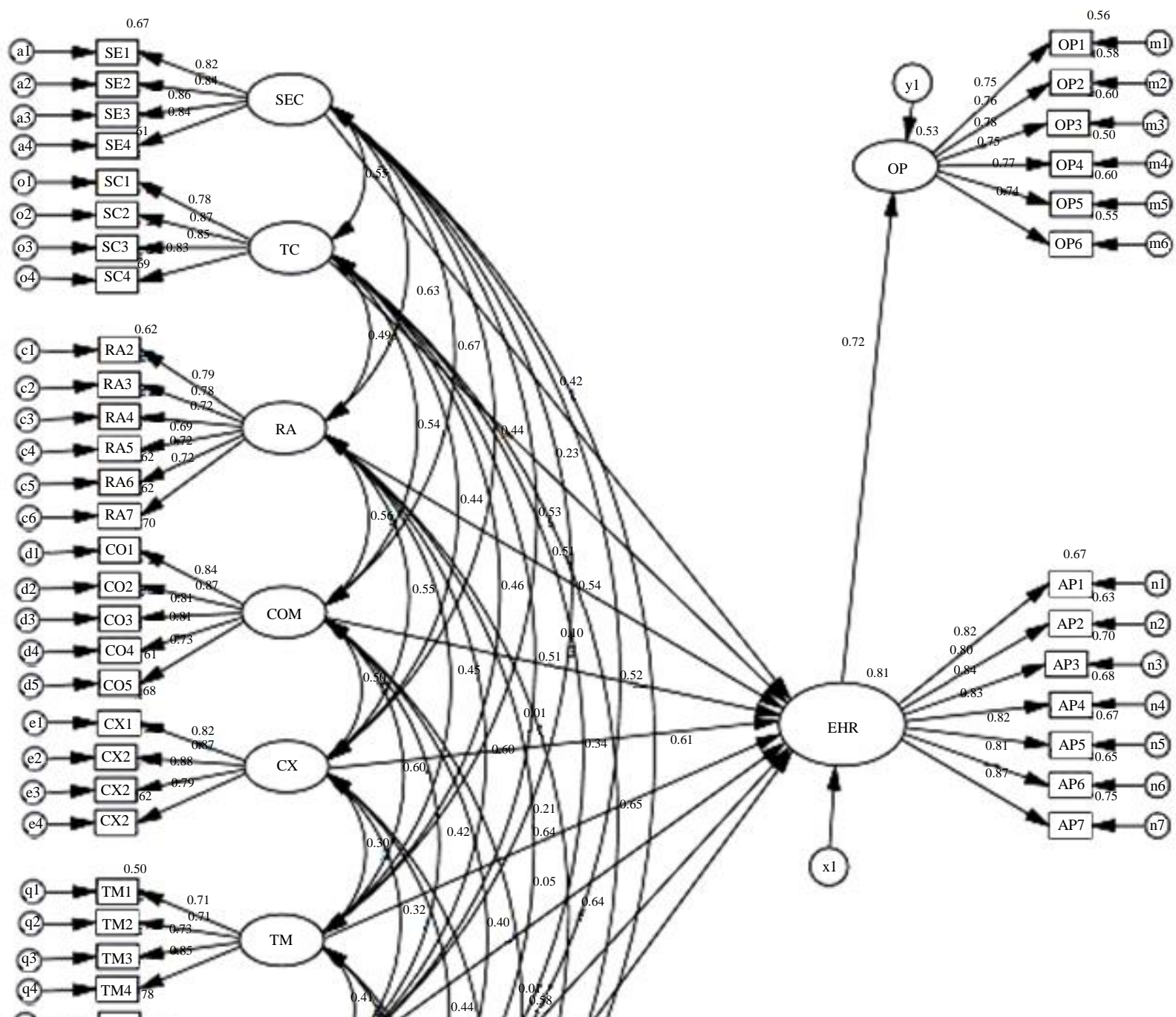

(94) $\rightarrow \mathrm{TM} 478$

(ii) $\longrightarrow \mathrm{OC} 1$

(i2) $\longrightarrow \mathrm{OC2}=-0.25$

(i1) $\longrightarrow \mathrm{OC} 3$

(i5) $\longrightarrow$ OC5

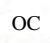

(i1) $-\mathrm{CP}^{0.50}$

(12) $\rightarrow \mathrm{CP} 3=\mathrm{CP}$

(i3) $\longrightarrow \mathrm{CP} 4$

(i4) $\rightarrow$ CP5

(11) $\rightarrow \mathrm{VS} 2 \mathrm{~W}$

(12) $\rightarrow \mathrm{VS} 3=\mathrm{Vs}=$

(K3) $\rightarrow \mathrm{VS4}$

(14) $\longrightarrow$ VS5

Fig. 3: Structural model 2 of proposed E-VALUE model without mediating variable 


\section{Discussion}

In this research, the proposed eVALUE model adds new knowledge to the existing literature of eHRM. The findings evident that there is strong association persist between eHRM practice and OP. Finally, the mediating effect of job satisfaction of HRM professionals is also investigated. In the proposed eVALUE model Fig. 1, drivers to eHRM application at organizational level are categorized into four key factors namely Human, organizational, technological and environmental context.

In human dimension, senior executives' attitude is identified as statistically significant factor that influencing the eHRM practice at organizational level. This result not only supports the findings of previous research in developing nations (Ahmad et al., 2015; Alshamaila et al., 2013; Ghobakhloo et al., 2011; Thong and Yap, 1995) but also confirms the results of research conducted in Western nations (Al-Qirim, 2007; Agarwal and Prasad, 1998). The finding also rejects the results of (Ahmadi et al., 2015; Lian et al., 2014). IT skill of HRM professionals is also recognized as statistically significant factor that inducing eHRM practice. Researchers argued that the lower the knowledge and skill barriers is, the more likely one firm will adopt IT applications. The results of previous research in developing nations support the finding of the current study (Ahmadi et al., 2015; Lian et al., 2014; Aboelmaged, 2014; Bian, 2012; Teo et al., 2007). Moreover, the results of research conducted in developed nations validate the finding of this study (Gutierrez et al., 2015; Oliveira et al., 2014; Troshani et al., 2011). However, the results are inconsistent with the previous research findings conducted on developing nations (Al-Dmour, 2014; Al-Mobaideen et al., 2013; Low et al., 2011).

In technological dimension, the result shows that relative advantage is statistically insignificant for eHRM practice. This result explored the eHRM practice in Bangladesh is not remarkably effected by the relative advantage. Possibly, it is due to non-recognition of the benefits of eHRM as an emerging technology in context of organizations of Bangladesh. The present result endorsees the earlier adoption research in developing and developed nations (Gutierrez et al., 2015; Lian et al., 2014; Al-Mobaideen et al., 2013; Bian, 2012). On the other hand, this result is inconsistent with the outcomes of studies conducted in developed nations (Oliveira et al., 2014; Ramdani et al., 2013; Al-Qirim, 2007). More notably, the result of this research shows inconsistency with what was found basing on the prior research done on developing nations (Ahmadi et al., 2015; Gangwar et al., 2015; Aboelmaged, 2014; Al-Dmour, 2014; Ghobakhloo et al., 2011; Low et al., 2011; Teo et al., 2007). The factor perceived compatibility was found to be statistically relevant for eHRM practice. So, the eHRM system deserves to be compatible with already available work procedures, values and beliefs and IT infrastructure in order to underscore and inculcate the practice of strategic HRM in organization. Consequently, it indicates that firms of Bangladesh realized that eHRM should be in line with the work guidelines and existing systems in the organization for effective and strategic HRM. This finding reaffirms the result of past studies (Masum et al., 2015a; Al-Dmour, 2014; Alshamaila et al., 2013; Bian, 2012). In contrast, this result ensues to be inconsistent compared to the preceding outcomes on IT innovation conducted in developing nations (Ahmadi et al., 2015; Lian et al., 2014; Low et al., 2011) and also in developed countries (Gutierrez et al., 2015; Oliveira et al., 2014). Unfortunately, the factor perceived complexity of the eHRM was not found to be statistically relevant factor for eHRM practice. Possibly, it is due to their experience with all available system in the organization which may reduce eHRM systems perceived complexity. The results are comply with the past research of some studies conducted on numerous IT modernization in developing countries, that found noteworthy association between IT modernization adoption and perceived complexity, especially in the Asian region (Ahmadi et al., 2015; Ahmad et al., 2015; Bian, 2012; Low et al., 2011; Teo et al., 2007) also in some developed countries such as New Zealand (Al-Qirim, 2007) and England (Alshamaila et al., 2013).

In organizational dimension, we have found that the senior leadership support is statistically significant for eHRM practice. So, that senior leadership support is crucial for adequate resource allocation and to eliminate every chances in-house resistance to eHRM practice. It is not only strengthen the adoption project but also remove every internal and external challenges, adoption resistance and difficulty and boost up the morality of project team. The results of previous research in developed countries validate the finding of this study (Alshamaila et al., 2013; Ramdani et al., 2013; Sila, 2013; Troshani et al., 2011). Moreover, the results of research conducted in developing countries support the finding of the current study (Gangwar et al., 2015; Al-Dmour, 2014; Oliveira et al., 2014; Lian et al., 2014; Bian, 2012; Low et al., 2011; Teo et al., 2009; 2007). However, the present result opposes the finding of the research on developing and developed countries where scholars stated senior leadership support as an insignificant factor in eHRM practice (Ahmadi et al., 2015; Gutierrez et al., 2015; Al-Mobaideen et al., 2013). The other factor of this dimension, firm culture is statistically relevant factor for eHRM practice in the context of Bangladesh. The previous research presented that the organizations' culture, values and selected work practices are associated with adoption of IT application (Al-Dmour, 2014; Indeje and Zheng, 2010). Similarly, (Jackson, 2011) attested that organizations which desired 
to adopt IT application in their enterprise essentially confirm that there is strong line up between the organization culture, the infrastructure and IT application. However, the current result confronts the findings of (Alkhater et al., 2018; Teo et al., 2009), who claimed that firm culture is not significant for implementing IT in business functions.

From environmental dimension, competitive pressure was revealed to be statistically significant that influencing eHRM practice. It meant the overall operational practices in an industry force the organizations to practice eHRM; ironically the high degree of pressure in HRM functions may derive poor eHRM practice in firms of Bangladesh. The finding of current paper is supported by previous research in developed nations (Gutierrez et al., 2015; Sila, 2013; Al-Qirim, 2007; Ramdani et al., 2013). Moreover, the results of research conducted in developing countries (Gangwar et al., 2015; Bian, 2012; Ghobakhloo et al., 2011; Al-Dmour, 2014; Low et al., 2011) support the finding of the current study. Conversely, many studies on developing and developed countries also confirmed the competitive pressure is not a significant influencer of eHRM practice in the organizations (Ahmadi et al., 2015; Lian et al., 2014; Oliveira et al., 2014; Aboelmaged, 2014; Ahmad et al., 2015; Teo et al., 2007). The factor of this dimension, the state patronization is evident as an insignificant factor of eHRM practice in the research. The government of the state can exclusively contribute in implementing IT adoption with providing many types of support namely enactment of friendly policy, provide national budget, facilitate the technological set, infrastructure, tax and subsidies and every other forms of patronization. Thus the findings of the study are relevant to prior research outcome underscored state patronization on IT use and applications leverage the firms decision to adopt IT at work (Ahmadi et al., 2015; Al-Dmour, 2014; Zhu and Kraemer, 2005). In reverse note, the finding of the study is not consistent by the previous research of (Lian et al., 2014; Oliveira et al., 2014) who contested that state patronization is not a significant factor.

Looking at eHRM practice, the variable acts as dependent variable (while assessing factors to eHRM practice) and independent variable (while it is in view of "eHRM practice-OP" relationship). However, a mediator variable (while assessing the indirect association) was used to evaluate the "eHRM practice-OP" relationship Fig. 2 and 3. Results suggest that eHRM practice and OP are directly related. The findings show that firm's planning to strengthen eHRM technology utilization. In other meaning, the findings recommend that business organizations should immediately initiate to the investment in eHRM adoption. In addition, external stakeholders for example like the government and industry trade associations should come forward to promoting investment in eHRM adoption. The previous studies claimed that IS/IT application is significantly influence organizational performance (Salwani et al., 2009; Grandon and Pearson, 2003). Thus, the current result is fairly relevant with the outcome of past research in context of developed and developing nations.

The result indicates eHRM practice has significant linear impact on OP and also significant non-linear impact on OP through the mediating construct - job satisfaction of HRM professionals. The mediation is partial. This result partially support the past studies of (Maier et al., 2013) where authors argued that job satisfaction of HRM professionals due to eHRM practice has a mediating role in eHRM adoption. They unveiled the research prove in favor of indirect effect of attitudes toward the eHRM adoption on employee quit intention that is fully mediated by task satisfaction. Similarly, (Chang et al., 2012) stated that system privacy, efficacy, user friendly in the ground of quality affect employee's job satisfaction, work performance and organizational commitment. The result of current study evident that adoption of eHRM system is predicted to be a tool of easy execution useful and usually produce positive spirit by HRM professionals is the prerequisite for having fullest satisfaction within the task in a compulsory eHRM diversified perspectives. We match this findings with eminent researcher of eHRM TV (Bondarouk and Ruël, 2013; Bondarouk et al., 2017) who called for inspection of a specific eHRM stakeholder- HRM professionals and (Maier et al., 2013), who attested the importance of considering HRM professional's perceptions during the adoption of eHRM.

\section{Conclusion}

The paper recommend that, at the organizational level, there are six factors such as senior executives' attitude, IT skills of HRM professionals, perceived compatibility, senior leadership support, firm culture and competitive pressure are the significantly influence eHRM practice. But, remaining three factors such as relative advantage, perceived complexity and state patronization have no strong influence on the eHRM practice at organizational level. The paper further claims that eHRM practice significantly influences OP. Additionally, the result of the paper revealed that organizational experience in eHRM significantly moderate the relationship of eHRM practice-OP.

The findings of the study is a reliable navigator as well as rich source to the owners, chief executives and other decision makers to broaden their window of knowledge about significant factors of eHRM practice, the necessity of using eHRM in business and measuring the post adoption effect. The findings will assist the operational managers in applying relevant transformation of technology within their organizations in Bangladesh. Essentially, the policy -makers of the firms should know the factors influencing the diffusion and adoption of eHRM applications and its effect and, thus each stakeholder will stimulate to get 
them ready to address unanticipated problems in adoption of IT innovation.

In future, the scope of the research in similar issues may be broader, will be able to explain the relationship more strongly if the sample size is larger. In addition, the specific focus on assessment of eHRM practice may discover manifold results and prospective researcher may use quantitative approach to judge their findings and real life outcomes. Before the end, the study thus advocate that some other potential influencer such as pressure from trade partner, data security, intensity of information etc. may incorporate in future research. In order to collect the data the study employed cross-sectional sample and survey technique a. At the conclusion, the study recommends a longitudinal study to produce more significant outcome instead of cross-sectional research.

\section{Acknowledgement}

The group of authors would like to express the sincere grateful and acknowledge Mohammed Shamsul Alam, Professor, International Islamic University Chittagong for his scholarly contribution in editing and proof reading this manuscript.

\section{Author's Contributions}

Abdul Kadar Muhammad Masum: Conceived and designed the experiments, performed the experiments, analyzed the data, contributed reagents/ materials/ analysis tools, wrote the paper, prepared figures and/or tables, reviewed drafts of the paper.

Abdullah Mohammad Ahsanul Mamun and Mohammad Shariful Islam: Performed the experiments, contributed reagents/materials/analysis tools, prepared figures and/or tables of the paper.

Loo-See Beh: Performed the experiments, contributed analysis tools, and reviewed drafts of the paper.

\section{Ethics}

The article is an absolute research by the authors and no part, sections been published anywhere. The corresponding author confirms that each of the authors has significantly contributed who have also read and approved the manuscript and no ethical issues involved.

\section{References}

Aboelmaged, M. G. (2014). Predicting e-readiness at firm-level: An analysis of technological, organizational and environmental (TOE) effects on e-maintenance readiness in manufacturing firms. International Journal of Information Management, 34(5), 639-651.
Agarwal, R., \& Prasad, J. (1998). The antecedents and consequents of user perceptions in information technology adoption. Decision support systems, 22(1), 15-29.

Ahmad, S. Z., Abu Bakar, A. R., Faziharudean, T. M., \& Mohamad Zaki, K. A. (2015). An empirical study of factors affecting e-commerce adoption among smalland medium-sized enterprises in a developing country: Evidence from Malaysia. Information Technology for Development, 21(4), 555-572.

Ahmadi, H., Nilashi, M., \& Ibrahim, O. (2015). Organizational decision to adopt hospital information system: An empirical investigation in the case of Malaysian public hospitals. International journal of medical informatics, 84(3), 166-188.

Alam, M. G. R., Masum, A. K. M., Beh, L. S., \& Hong, C. S. (2016). Critical factors influencing decision to adopt human resource information system (HRIS) in hospitals. PloS one, 11(8), e0160366.

Al-Dmour, R. (2014). An integration model for identifying the determinants of the adoption and implementation level of HRIS applications and Its effectiveness in business organisations in Jordan (Doctoral dissertation).

Alkhater, N., Walters, R., \& Wills, G. (2018). An empirical study of factors influencing cloud adoption among private sector organisations. Telematics and Informatics, 35(1), 38-54.

Al-Mobaideen, H., Allahawiah, S., \& Basioni, E. (2013). Factors influencing the successful adoption of human resource information system: The content of Aqaba special economic zone authority.

Al-Qirim, N. (2007). The adoption of eCommerce communications and applications technologies in small businesses in New Zealand. Electronic Commerce Research and Applications, 6(4), 462-473.

Alshamaila, Y., Papagiannidis, S., \& Li, F. (2013). Cloud computing adoption by SMEs in the north east of England: A multi-perspective framework. Journal of Enterprise Information Management, 26(3), 250-275.

Ankrah, E., \& Sokro, E. (2016). Intention and usage of human resource information systems among ghanaian human resource managers. International Journal of Business and Management, 11(2), 241.

Armstrong, J. S., \& Overton, T. S. (1977). Estimating nonresponse bias in mail surveys. Journal of marketing research, 14(3), 396-402.

Ashraf, M. A., Tawhid, A. A. M., Masum, A. K. M., Al Abid, F. B., Ahmed, S. A., \& Khan, S. I. (2019, December). Performance Evaluation of IT Professionals Based on Fuzzy-AHP and DEMATEL Models: Bangladesh Perspective. In 2019 22nd International Conference on Computer and Information Technology (ICCIT) (pp. 1-5). IEEE. 
Azhdari, G., Lagzian, M., Shirazi, A., \& Fayyazi, M. (2019). Electronic human resource management adoption model in knowledge base small and medium enterprises. Iranian Journal of Information Processing Management, 34(2), 535-556.

Bartlett, M. S. (1954). A note on the multiplying factors for various $\chi^{2}$ approximations. Journal of the Royal Statistical Society. Series B (Methodological), 296-298.

Beckers, A. M., \& Bsat, M. Z. (2002). A DSS classification model for research in human resource information systems. Information Systems Management, 19(3), 41-50.

Bhuiyan, M. R. U., \& Rahman, M. R. (2014). Application of human resource information system in the firms of Bangladesh and its strategic importance. World Review of Business Research, 4(3), 95-105.

Bian, L. (2012). An empirical study on factors that influencing the adoption of electronic human resource management (E-HRM) among firms in northeast of China/Bian Linlin (Doctoral dissertation, University of Malaya).

Bondarouk, T., \& Ruël, H. (2013). The strategic value of eHRM: results from an exploratory study in a governmental organization. The International Journal of Human Resource Management, 24(2), 391-414.

Bondarouk, T., Parry, E., \& Furtmueller, E. (2017). Electronic HRM: four decades of research on adoption and consequences. The International Journal of Human Resource Management, 28(1), 98-131.

Chang, C. S., Chen, S. Y., \& Lan, Y. T. (2012). Motivating medical information system performance by system quality, service quality, and job satisfaction for evidence-based practice. BMC Medical informatics and decision making, 12(1), 135.

Chowdhury, M. A., Yunus, M., Bhuiyan, F., \& Kabir, M. R. (2013, December). Impact of human resources information system (HRIS) on the performance of firms: a study on some selected bangladeshi banks. In 9th Asian Business Research Conference BIAM Foundation, Dhaka, Bangladesh2013.

Cooper, D. R., Schindler, P. S., \& Sun, J. (2003). Business research methods.

Davis, F. D. (1989). Perceived usefulness, perceived ease of use, and user acceptance of information technology. MIS quarterly, 319-340.

Dezdar, S. (2011). Critical factors affecting enterprise resource planning implementation success (Doctoral dissertation, Universiti Malaya).

Gangwar, H., Date, H., \& Ramaswamy, R. (2015). Understanding determinants of cloud computing adoption using an integrated TAM-TOE model. Journal of enterprise information management.
Ghobakhloo, M., Arias-Aranda, D., \& Benitez-Amado, J. (2011). Adoption of e-commerce applications in SMEs. Industrial Management \& Data Systems.

Grandon, E., \& Pearson, J. M. (2003). Strategic value and adoption of electronic commerce: an empirical study of Chilean small and medium businesses. Journal of Global Information Technology Management, 6(3), 22-43.

Gutierrez, A., Boukrami, E., \& Lumsden, R. (2015). Technological, organisational and environmental factors influencing managers' decision to adopt cloud computing in the UK. Journal of Enterprise Information Management, 28(6), 788-807.

Hair, J. F., Black, W. C., \& Babin, A. (2010). RE and Tatham, RL (2006), Multivariate Data Analysis.

Hofstede, G. (2001). Culture's consequences: Comparing values, behaviors, institutions and organizations across nations. Sage publications.

Imron, M. I. R., Hidayanto, A. N., Fitriani, W. R., Nugroho, W. S., \& Inan, D. I. (2019, October). Analysis of Cloud-Based Human Resource Information System Adoption Factors Prioritization in Micro, Small, and Medium Enterprises. In 2019 International Conference on Advanced Computer Science and information Systems (ICACSIS) (pp. 295-300). IEEE.

Indeje, W. G., \& Zheng, Q. (2010). Organizational culture and information systems implementation: A structuration theory perspective. Working Papers on Information Systems ISSN, 1535-6078.

Al Mamun, M. A., \& Islam, M. S. (2016). Perception of management on outcomes of human resource information system (HRIS). International Journal of Business and Social Research, 6(2), 29-37.

Jackson, S. (2011). Organizational culture and information systems adoption: A three-perspective approach. Information and Organization, 21(2), 57-83.

Jahan, S. S. (2014). Human resources information system (HRIS): A theoretical perspective. Journal of Human Resource and Sustainability Studies, 2014.

Kauffman, R. J., Wang, B., \& Miller, T. (2002, January). Strategic'Morphing'and the Survivability of Ecommerce Firms. In Proceedings of the 35th Annual Hawaii International Conference on System Sciences (pp. 2930-2939). IEEE.

Katou, A., \& Budhwar, P. (2006). The effect of human resource management systems on employee performance: Test of a mediating model. International Journal of Human Resource Management, 17(7), 1223-1253.

Khan, A. R., Hasan, N., \& Rubel, M. (2015). Factors affecting organizations adopting human resource information systems: A study in Bangladesh. J. Bus. Manage, 17, 45-54.

Kuan, K. K., \& Chau, P. Y. (2001). A perception-based model for EDI adoption in small businesses using a technology-organization-environment framework. Information \& management, 38(8), 507-521. 
Krumbholz, M., \& Maiden, N. (2001). The implementation of enterprise resource planning packages in different organisational and national cultures. Information systems, 26(3), 185-204.

Lian, J. W., Yen, D. C., \& Wang, Y. T. (2014). An exploratory study to understand the critical factors affecting the decision to adopt cloud computing in Taiwan hospital. International Journal of Information Management, 34(1), 28-36.

Low, C., Chen, Y., \& Wu, M. (2011). Understanding the determinants of cloud computing adoption. Industrial management \& data systems.

Maier, C., Laumer, S., Eckhardt, A., \& Weitzel, T. (2013). Analyzing the impact of HRIS implementations on HR personnel's job satisfaction and turnover intention. The Journal of Strategic Information Systems, 22(3), 193-207.

Marler, J. H., \& Fisher, S. L. (2013). An evidence-based review of e-HRM and strategic human resource management. Human resource management review, 23(1), 18-36.

Masum, A. K. M. (2015). Adoption Factors of Electronic Human Resource Management (e-HRM) in Banking Industry of Bangladesh. Journal of Social Sciences/Sosyal Bilimler Dergisi, 11(1).

Masum, A. K. M., Bhuiyan, F., \& Kabir, R. (2013). HRIS practices in universities: An exploratory study on the private universities in Bangladesh. Global $\mathbf{J}$. Hum. Soc. Sci. Res.

Masum, A. K. M., Beh, L. S., Azad, M. A. K., \& Hoque, K. (2018). Intelligent human resource information system (i-HRIS): a holistic decision support framework for HR excellence. Int. Arab J. Inf. Technol., 15(1), 121-130.

Masum, A. K. M., Azad, M. A. K., \& Beh, L. S. (2015a). Determinants of academics' job satisfaction: Empirical evidence from private universities in Bangladesh. PloS one, 10(2), e0117834.

Masum, A. K. M., Azad, M. A. K., Hoque, K. E., \& Beh, L. S. (2015b). Domestic banks in Bangladesh could ensure efficiency by improving human resource management practices. PloS one, 10(7), e0121017.

Masum, A. K. M., Kabir, M. J., \& Chowdhury, M. M. $(2015 \mathrm{c})$. Determinants that influencing the adoption of E-HRM: An empirical study on Bangladesh. Asian Social Science, 11(21), 117.

Masum, A. K. M., Alam, M. G. R., Alam, M. S., \& Azad, M. A. K. (2016a, October). Adopting factors of electronic human resource management: Evidence from Bangladesh. In 2016 International Conference on Innovations in Science, Engineering and Technology (ICISET) (pp. 1-4). IEEE.

Masum, A. K. M., Azad, M. A. K., Hoque, K. E., Beh, L. S., Wanke, P., \& Arslan, Ö. (2016b). Job satisfaction and intention to quit: An empirical analysis of nurses in Turkey. PeerJ, 4, e1896.
Moore, G. C., \& Benbasat, I. (1991). Development of an instrument to measure the perceptions of adopting an information technology innovation. Information systems research, 2(3), 192-222.

Nunnally, C.J, (2010). Psychometric Theory Noida, UP. 1st Edn., Tata McGraw-Hill Education, India,

Oliveira, T., Thomas, M., \& Espadanal, M. (2014). Assessing the determinants of cloud computing adoption: An analysis of the manufacturing and services sectors. Information \& Management, 51(5), 497-510.

Pallant, J, (2011). SPSS Survival Manual: A Step by Step Guide to Data Analysis Using IBM SPSS. Allen and Unwin, Sydney.

Panayotopoulou, L., Vakola, M., \& Galanaki, E. (2007). E-HR adoption and the role of HRM: Evidence from Greece. Personnel Review.

Parry, E. (2011). An examination of e-HRM as a means to increase the value of the HR function. The International Journal of Human Resource Management, 22(05), 1146-1162.

Penrose, E, (2009). The Theory of the Growth of the Firm. Oxford university press.

Premkumar, G. (1999). Roberts. M," Adoption of new IT in rural small business. Omega, 27, 467-484.

Quaosar, G. A. A., Hoque, M. R., \& Bao, Y. (2018). Investigation on the precursors to and effects of human resource information system use: The case of a developing country. Cogent Business \& Management, 5(1), 1485131.

Ramdani, B., Chevers, D., \& Williams, D. A. (2013). SMEs' adoption of enterprise applications: A technology-organisation-environment model. Journal of Small Business and Enterprise Development, 20(4), 735-753.

Ruël, H., \& Van der Kaap, H. (2012). E-HRM usage and value creation. Does a facilitating context matter? German Journal of Human Resource Management, 26(3), 260-281.

Salwani, M. I., Marthandan, G., Norzaidi, M. D., \& Chong, S. C. (2009). E-commerce usage and business performance in the Malaysian tourism sector: Empirical analysis. Information Management \& Computer Security.

Seif, J. K. (2015). Challenges of Adopting Human Resource Information Systems in the Information Technology Industry in Kenya: A Survey Of Selected It Firms (Doctoral dissertation, United States International University-Africa).

Shiu, Y. M., \& Yu, T. W. (2010). Internal marketing, organisational culture, job satisfaction, and organisational performance in non-life insurance. The Service Industries Journal, 30(6), 793-809. 
Sila, I. (2013). Factors affecting the adoption of B2B ecommerce technologies. Electronic commerce research, 13(2), 199-236.

Škudienè, V., Vezeliene, G., \& Stangej, O. (2020). Transforming human resource management: innovative e-HRM value creation for multinational companies. In Innovation Management. Edward Elgar Publishing.

Strohmeier, S. (2007). Research in e-HRM: Review and implications. Human resource management review, 17(1), 19-37.

Teo, T. S., Lim, G. S., \& Fedric, S. A. (2007). The adoption and diffusion of human resources information systems in Singapore. Asia Pacific Journal of Human Resources, 45(1), 44-62.

Teo, T. S., Lin, S., \& Lai, K. H. (2009). Adopters and non-adopters of e-procurement in Singapore: An empirical study. Omega, 37(5), 972-987.
Thong, J. Y., \& Yap, C. S. (1995). CEO characteristics, organizational characteristics and information technology adoption in small businesses. Omega, 23(4), 429-442.

Tornatzky, L. G., Fleischer, M., \& Chakrabarti, A. K. (1990). Processes of technological innovation. Lexington books.

Troshani, I., Jerram, C., \& Hill, S. R. (2011). Exploring the public sector adoption of HRIS. Industrial Management \& Data Systems.

Yusof, M. M., Papazafeiropoulou, A., Paul, R. J., \& Stergioulas, L. K. (2008). Investigating evaluation frameworks for health information systems. International journal of medical informatics, 77(6), 377-385

Zhu, K., \& Kraemer, K. L. (2005). Post-adoption variations in usage and value of e-business by organizations: cross-country evidence from the retail industry. Information systems research, 16(1), 61-84. 